\title{
Ensinando geometria plana através de mosaicos com a ajuda de um objeto de aprendizagem no padrão RIVED
}

\author{
Cristiano L. Lima* \\ Eduardo M. Luchessi** \\ Paula Aguiar da Silva*** \\ Ricardo F. Jardim**** \\ Marcus Vinícius de Azevedo Basso*****
}

\begin{abstract}
Resumo. O presente artigo trata da construção de um objeto aprendizagem de geometria plana voltado aos alunos do ensino médio, através de atividades de simulação de pavimentação e da utilização de conceitos de mosaicos para o projeto RIVED (Rede Internacional Virtual de Educação). Trata também a vantagem do uso de objetos virtuais de aprendizagem nas salas de aula, bem como discute brevemente os conceitos e padrões dos objetos do RIVED.
\end{abstract}

\begin{abstract}
The present article deals with the construction of an Object of Learning (OL) of plain geometry directed of average education. Creating and manipulating geometric forms during activities of simulation of the pavement of one house, using references in mosaics of different places of the world (that they compose the OL and in research form proposal) directed by the professor, the pupils also go constructing and reaffirming concepts by means of the exchange of ideas between itself of synchronous form in the environment of the OL. We treat to the advantages of the use of virtual OL in the classrooms, as well as we briefly argue the concepts and standards dictated for the (Rede Internacional Virtual de Educação) here used.
\end{abstract}

\footnotetext{
* Aluno de Curso Técnico da UFRGS e graduando Bacharelado em Matemática UFRGS; bolsista do Laboratório de Estudos Cognitivos da UFRGS; cristiano@lec.ufrgs.br

** Graduando de Licenciatura em Matemática da UFRGS; bolsista do Laboratório de Estudos Cognitivos da UFRGS; eml7171@yahoo.com.br

*** Graduanda de Licenciatura em Matemática da UFRGS; bolsista do Laboratório de Estudos Cognitivos da UFRGS; paulaasmini@yahoo.com.br

**** Graduando de Licenciatura em Matemática da UFRGS; bolsista do Laboratório de Estudos Cognitivos da UFRGS; ricardo.jardim@gmail.com

***** Professor do Instituto de Matemática - UFRGS - Pesquisador do Laboratório de Estudos

Cognitivos - UFRGS; mbasso@ufrgs.br 


\section{Introdução}

Apresentamos nesse trabalho o resultado de um treinamento desenvolvido no RIVED - SEED - MEC com estudantes de ensino técnico e de graduação de cursos de licenciatura por um período de quatro meses. Salientamos o paradigma orientador do Projeto RIVED com a aplicação dos princípios da UNESCO: fazendo, desenvolvendo, compreendendo e reconstruindo.

O RIVED (Rede Internacional Virtual de Educação) é um projeto que elabora módulos educacionais digitais visando à melhoria do processo de ensino/aprendizagem das ciências e matemática no Ensino Médio, além de incentivar o uso de novas tecnologias em nossas escolas. Desenvolvido no Ministério da Educação do Brasil pelas Secretarias de Educação a Distância - SEED e Secretaria de Educação Básica - SEB, conta hoje com uma equipe central multidisciplinar, responsável pela metodologia do processo de produção dos módulos.

Com o auxilio de objetos virtuais de aprendizagem um professor pode simular uma atividade prática no computador (mosaicos, no caso descrito) sem a necessidade da manipulação real do material e, desta maneira, reduzindo custos e tempo de produção, além da possibilidade de reutilização deste objeto sob várias abordagens pedagógicas.

Os objetos educacionais geralmente não possuem um padrão linear de interatividade para o usuário seguir, assim o usuário pode interagir livremente dando prosseguimento ao estudo objetivado pelo objeto de acordo com o seu grau de conhecimento do assunto.

Segundo nossa concepção, um objeto de aprendizagem deve possibilitar/possibilitar ao aluno contato com situações-problema difíceis de serem manipuladas no real e onde eles possam agir sobre tal situação/ambiente e obter questões/dúvidas que o desequilibrem e que assim, manipulando os recursos fornecidos pelo objeto, o aluno possa ir reorganizando seus esquemas mentais e aprendendo. Tal visão do grupo provocou uma "abertura" muito grande de novas idéias, outros conceitos que poderiam ser abordados pelo objeto, o que foi exigindo do mesmo um grau cada vez maior de interatividade e número maior de recursos para os alunos.

\section{Vantagens do Uso de Objetos Virtuais de Aprendizagem}

Através dos objetos virtuais, alunos podem não só fazer simulação da manipulação de objetos em multimídia como também usar um ambiente totalmente interativo e não-linear voltado a uma diversidade de abordagens pedagógicas interdisciplinares, assim os professores de um mesmo grupo de alunos poderão utilizarse do mesmo objeto sob vários aspectos, com um custo muito baixo.

Além disso, com o uso do OA possibilita-se ao aluno maior agilidade em fazer e desfazer ações, com o intuito de que assim ele seja capaz de reconstruir seu sistema de significação, realizando metacognição sobre os esquemas adquiridos.

Apresentando os conceitos que se deseja trabalhar, aplicados diretamente em situações reais, a questões ligadas ao dia-a-dia, estaremos justificando seu aprendizado ao estudante. Ao permitir que ele manipule os objetos e modifique propriedades para que se ajustem a determinadas expectativas, suas e nossas, que "brinque" com os conceitos que já possui, estará ampliando seu entendimento, estará fazendo novas relações mentais, fazendo "descoberta" de conceitos e de aplicações relativas ao que se 
está trabalhando. A medida que interage com o objeto, conceitos que então, existem apenas no seu pensamento vão ganhando uma forma, ou melhor, uma formalização que permitirá a ele não só reconhecê-la fora do mundo mental mas que esteja capacitado a compartilhar idéias, escritas ou verbais, com os demais. As identificações que acabará criando entre o objeto e ele próprio, as experiências pessoais que utiliza nas descobertas, é que tornarão interessante, todo esse processo.

Os Objetos influenciam na aprendizagem em sala de aula, dirimindo as dúvidas iniciais que o professor não percebe no momento quando propõem a abstração (por ter muitos alunos ou pela vergonha perante os colegas, etc.) e que podem se tornar entraves definitivos na seqüência da aprendizagem de um conteúdo. Trazendo maior diversidade de situações para sala de aula, permitindo uma maior interatividade objeto/aluno. Permitindo simulações e interações e ampliando possibilidades que de outro modo não seriam viáveis. A transformação de algo concreto - um tijolo, para uma abstração - um paralelepípedo, manipulando o objeto na tela é como se manipulasse, ele próprio, um meio termo entre o concreto e o abstrato apenas mentalmente. Não fica limitado ao desenho que o professor faz no quadro, tem grande liberdade nesse momento de agir para se esclarecer. Contando também com as questões de apoio que vão surgindo durante as atividades, com o compartilhamento síncrono de idéias com colega e com o professor o ambiente que se cria se bem elaborado e bem conduzido é um catalisador poderoso no processo de aquisição de um conteúdo.

\section{O Formato Rived}

A Rede Internacional Virtual de Educação prevê uma série de padrões para a construção dos objetos de aprendizagem pelas equipes. Estes vão desde a separação de funções na equipe até a indicação de formatos para os botões a serem colocados no próprio objeto.

\section{1 - A equipe}

A equipe é composta por sete membros, sendo três destes responsáveis pela parte pedagógica do objeto, escolhendo um tópico a ser trabalhado e construindo o objeto sob uma fundamentação psico-pedagógica.

Dois outros membros da equipe trabalham na parte de programação do objeto de aprendizagem, sendo assim responsáveis pela digitalização do material já produzido.

$\mathrm{E}$ os outros dois restantes são os coordenadores e orientadores da equipe, que se incubem, um da parte técnica e outro da parte psico-pedagógica.

\section{2- Construção do Objeto}

Após a escolha de um tema a ser trabalhado no objeto, a equipe deve trabalhar no "General Design" (GD), que orientará a parte técnica da equipe no desenvolvimento do objeto. Após a construção pela equipe técnica do objeto planejado foi desenvolvido um guia do professor a fim de orientar os educadores no manuseio do objeto e responder perguntas que estes possam vir a ter em relação à aplicação do objeto.

\section{O Objeto de Aprendizagem}

O objeto por nós desenvolvido visa ampliar o conhecimento de jovens cursando o início do ensino médio sobre a geometria plana, tendo que construir para isso um mosaico para a pavimentação do piso de uma sala. 
Tem por objetivo que o educando através de atividades exploratórias possa construir conceitos geométricos. O objeto oferece recursos para o aluno explorar as propriedades dos diferentes elementos do OA e realizar atividades operatórias de compor e decompor, criando padrões e aplicando transformações no plano.

Fazendo uso de redes locais ou globais, pautamos a criação das atividades e os aspectos relativos a interatividade, pelo seguinte esquema conceitual:

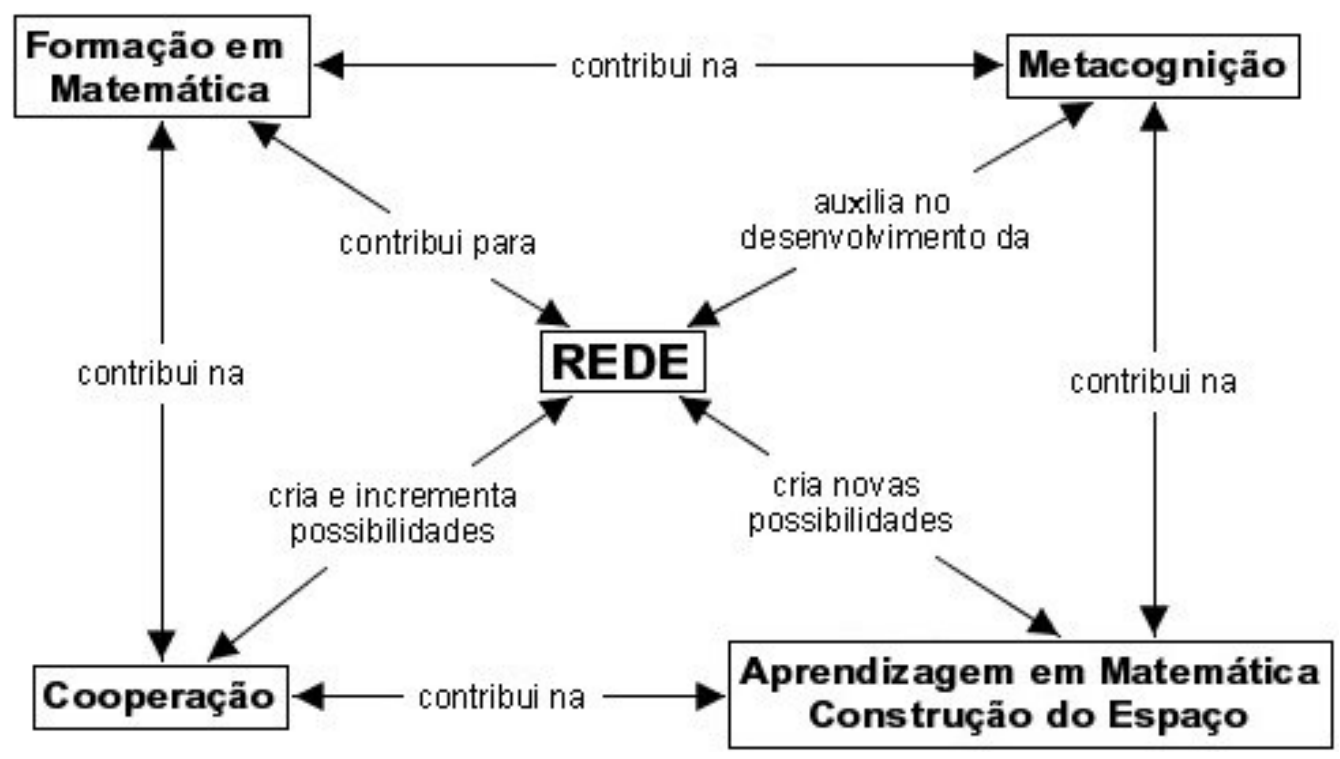

Durante a atividade exploratória espera-se que o aprendiz observe e caracterize as propriedades geométricas através de coordenações e inferências e possa tanto aprimorar seus sistemas de significação quanto as operações lógico-matemáticas que sejam aplicáveis à leitura de sua experiência.

Os objetos da geometria podem ser representados de modo gráfico, material, porém seu trabalho matemático envolve abstração do real e implicam na utilização de um conjunto de relações lógico-matemáticas.

Observando deficiência do ensino matemático Brasileiro de tal abstração, o grupo se interessou pelo tópico em busca de nova abordagem que auxiliasse os professores. Além disso, conhecer Geometria permite que se elaborem modelos da realidade e que se resolvam diversos problemas práticos, como por exemplo, nas áreas de Arquitetura, Engenharia, Geografia, Artes Plásticas, planejamento urbano e regional, design de superfície, etc.

Podemos citar algumas aplicações:

- Projeto de mosaicos artísticos em cerâmicas, tapeçaria, vitrais e outras formas de decoração;

- Aplicações na Arquitetura, na Engenharia para determinação de moldes e peças;

- Seccionamento de sólidos em estruturas de engenharia e o estudo de curvas de nível em cartografia;

- Fotogrametria (fotografias aéreas). 
Quanto às atividades propostas, o objeto divide-se basicamente em duas tarefas de dificuldades distintas, em que o aluno pode, se desejar, avançar progressivamente. Na primeira atividade será necessário pavimentar o piso de uma sala apenas com peças regulares, explicando quantas peças teve que utilizar e o porquê da escolha. $\mathrm{O}$ aluno, durante a pavimentação virtual, também é questionado por várias perguntas anteriormente definidas pelo professor em um arquivo em linguagem XML próprio para este fim. Na segunda atividade o aluno deverá pavimentar a mesma sala apenas com polígonos irregulares, explicando também a sua construção no fim. Após cada atividade o aluno responde a um desafio sobre o conteúdo tratado. Tais desafios não exigem conhecimentos específicos maiores do que os já utilizados para a construção e respostas durante a construção, mas sim raciocínio lógico sobre as construções mostradas.

Existem inserido no OA diversos textos de apoio tanto ao aluno como ao professor/monitor. Entre eles estão os textos de ajuda sobre o uso do objeto, informações sobre geometria e sobre mosaicos previamente pesquisados, links sobre aos mosaicos, o que são, onde se encontram, como são feitos, além de sugestões de pesquisa na web. O material do professor contém a descrição do objeto e várias sugestões de atividades e faz referência as questões pedagógicas contidas no ambiente. $\mathrm{O}$ texto de apoio esta acessível sempre, mas não é o foco central do objeto. Quando o aluno sentir necessidade de mais informação irá de encontro do material, permitindo a reflexão e mantendo o interesse, como uma pista para alcançar o objetivo. É uma das formas de interação mais importante. Ele não substitui o professor/monitor mas ajuda na contextualização da atividade.

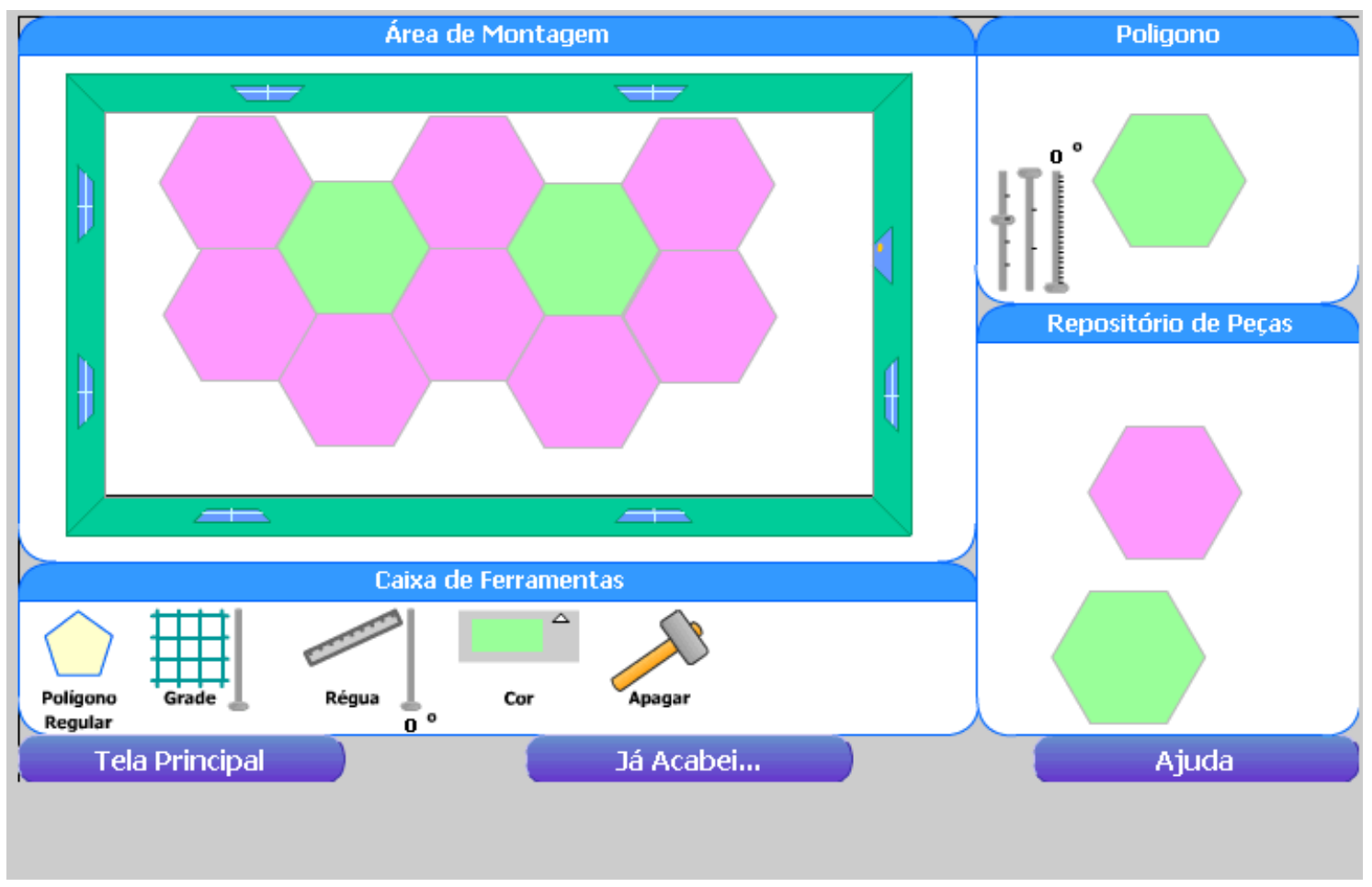

\subsection{Objetivos:}

Aqui estão dispostos objetivos que o grupo tem para, utilizando o objeto de aprendizagem, desenvolver:

- Comparar figuras planas considerando sua superfície; 
- Aplicar o conceito de unidade medida no uso de ferramentas e formalizar os procedimentos da medição de área;

- Realizar medições de superfície com escalas diferentes de medida, abordando proporcionalidade;

- Observar, reconhecer e descobrir padrões em pavimentações e etc.;

- Desenvolver competências de cooperação, discutindo decisões e seus diferentes resultados com os dos colegas durante todas as atividades;

- Emitir conceitos formais individualmente, em forma de material descritivo num formulário específico, em que todos possam ler as contribuições de cada um.

- Relacionar os ângulos internos e externos das figuras com as possibilidades de implementação da sua pavimentação;

- Experimentar a construção possível de pavimentos com polígonos relativos ao conceito de ângulo externo e interno;

- Classificar polígonos;

- Manipular com confiança e relacionar os conceitos geométricos com problemas práticos;

- Formalizar problemas práticos e solucioná-los com o uso da Geometria;

- Aplicar transformações geométricas que facilitem na resolução de problemas;

- Fazer e desfazer movimentos rígidos com polígonos;

- Identificar simetrias em mosaicos construídos ou em construção;

- Criar modelos fazendo composições entre polígonos.

\subsection{Questões para discussão}

Para uma melhor compreensão das aulas a serem dadas com o auxílio do objeto de aprendizagem criado, são abaixo sugeridas algumas questões para a discussão com os aprendizes. Apesar de não ser obrigatório, seu uso é incentivado durante a utilização do objeto.

\section{Quanto aos Polígonos Regulares:}

1. O que é um Mosaico?

2. O que é uma figura poligonal e o que não é uma figura poligonal?

3. Quantos Polígonos Regulares existem? Quais são eles?

4. Como se faz para medir um polígono, como saber se um polígono é maior que outro?

5. Qual a utilidade de medir um polígono? Quem precisa saber disso?

6. Polígonos diferentes podem ter a mesma dimensão? O que é dimensão?

7. Alguns Polígonos Regulares se encaixam perfeitamente. Quando justapostos, não se sobrepõem e nem resta qualquer buraco (espaço) entre eles. Quais são eles?

8. Como as Pavimentações são inventadas?

9. O que é ampliação? O que é redução? O que é rotação? O que é simetria? O que é translação?

\section{Polígonos Irregulares}

10. Uma circunferência é um polígono? Se for de que tipo?

11. É possível construir mosaicos com todos os tipos de triângulos? (eqüilátero, isósceles, escaleno)

12. É possível construir mosaico com todos os quadriláteros?(retângulo, losango, trapézio, paralelogramo, quadrilátero qualquer)

13. É possível construir um mosaico usando apenas quadrados e octógonos. Será que você consegue? 


\section{Quanto aos Sólidos:}

14. É possível planificar um cubo? E uma pirâmide? E um prisma triangular? E um cilindro? E um cone?

15. Existe algum sólido que não possa ser planificado?

16. Qual figura plana aparece quando seccionamos um paralelepípedo paralelamente à base? E se seccionando obliquamente?

17. Qual figura plana aparece quando seccionamos um cilindro paralelamente à base? E se seccionando obliquamente?

18. Qual figura plana aparece quando seccionamos uma pirâmide paralelamente à base? E se seccionando obliquamente?

19. Qual figura plana aparece quando seccionamos um cone paralelamente à base? E se seccionando oblicuamente?

\subsection{Texto de Apoio}

Existem inseridos no OA diversos textos de apoio tanto ao aluno como ao professor/monitor. Entre eles estão os textos de ajuda sobre o uso do objeto, informações sobre geometria e sobre mosaicos previamente pesquisados, links sobre aos mosaicos, o que são, onde se encontram, como são feitos, além de sugestões de pesquisa na web. O material do professor contém a descrição do objeto e várias sugestões de atividades e fazem referência as questões pedagógicas contidas no ambiente.

O texto de apoio esta acessível sempre, mas não é o foco central do objeto. Quando o aluno sentir necessidade de mais informação irá de encontro do material, permitindo a reflexão e mantendo o interesse, como uma pista para alcançar o objetivo. É uma das formas de interação mais importante. atividade.

Ele não substitui o professor/monitor mas ajuda na contextualização da

\subsection{Estrutura Técnica do Objeto}

O objeto quanto à estrutura técnica teve suas definições discutidas com toda a equipe (coordenação, pedagógica e técnica), num trabalho de definição dos principais pilares do desenvolvimento foi estipulado que o OA seria voltado para uma utilização de muitos usuários ao mesmo tempo, preferencialmente em uma rede local previamente preparada para tal fim, os usuários deveriam manipular conjuntamente uma série de conceitos sobre mosaicos, com isso, o objeto tem como principal característica o trabalho em conjunto. Para tanto foram definidas algumas estruturas básicas para a utilização do objeto, como:

- O OA deve ser configurado na rede a partir de um dos terminais, que terá o papel de repositório das atividades em forma de arquivos XML. Estes conterão informações como respostas dadas aos questionamentos propostos, informações do usuário e dados de manipulação do objeto.

- O ambiente de utilização do objeto será um cliente socket que enviará as informações ao repositório, sempre que for dada a ação de submissão destas.

- Por escolha da equipe o objeto não restringe a ninguém a utilização do objeto, por isso dados como informações de usuários serão fornecidas opcionalmente pelo próprio usuário. Mas para coordenação dos acessos sempre são passadas informações da máquina que enviou os arquivos. 
A escolha do Macromedia Flash como plataforma de desenvolvimento do objeto deu-se pela facilidade de implementação deste software em diferentes ambientes de trabalho, tais como diferentes tipos de sistemas operacionais e navegadores web, o que facilita a utilização do OA em diversos contextos de trabalho. Além do fato de se obter um melhor ambiente de utilização do objeto que poderá contar com comandos simples e de fácil compreensão.

O Objeto da Aprendizagem apresentado utiliza a programação orientada a objetos (POO) facilitando a reutilização dos conceitos já abordados sobre ele, a utilização do Macromedia Flash MX 2004 facilitou a padronização numa linguagem altamente robusta, o que possibilitou e ajudou o trabalho da equipe técnica num ambiente estruturado de programação. No contexto de Objetos de Aprendizagem a POO se faz necessária pelo fato de permitir que muitas pessoas utilizem-se dos códigos desenvolvidos e até mesmo modifiquem-no para a sua melhor funcionalidade no ambiente requerido. Assim permitindo uma maior interdisciplinaridade entre os diferentes objetos, pois se pode fazer uso dos conceitos de outros objetos em um novo, além do fato de facilitar a interpretação do que está sendo feito a cada momento da programação do objeto, e assim permitir que o professor altere a funcionalidade do objeto como necessitar.

\section{Considerações Finais}

Os objetos de aprendizagem têm hoje um papel cada vez maior na educação a distância. É provável que em um futuro próximo seu uso seja amplamente divulgado também em escolas públicas tradicionais. O conhecimento dos métodos de construção, assim como toda a pedagogia oculta na construção do objeto se farão necessários muito em breve para a elaboração de objetos cada vez mais complexos, porém mais leves. Através do projeto RIVED, pudemos ampliar nossos conhecimentos na construção de objetos, tendo aulas de educação a distância e trabalhando em equipe e superando desafios na construção de um novo objeto criado por nós. A experiência foi bastante gratificante para todos nós, inclusive pedagogicamente, principalmente durante a aplicação dos objetos criados por nós a alunos. 


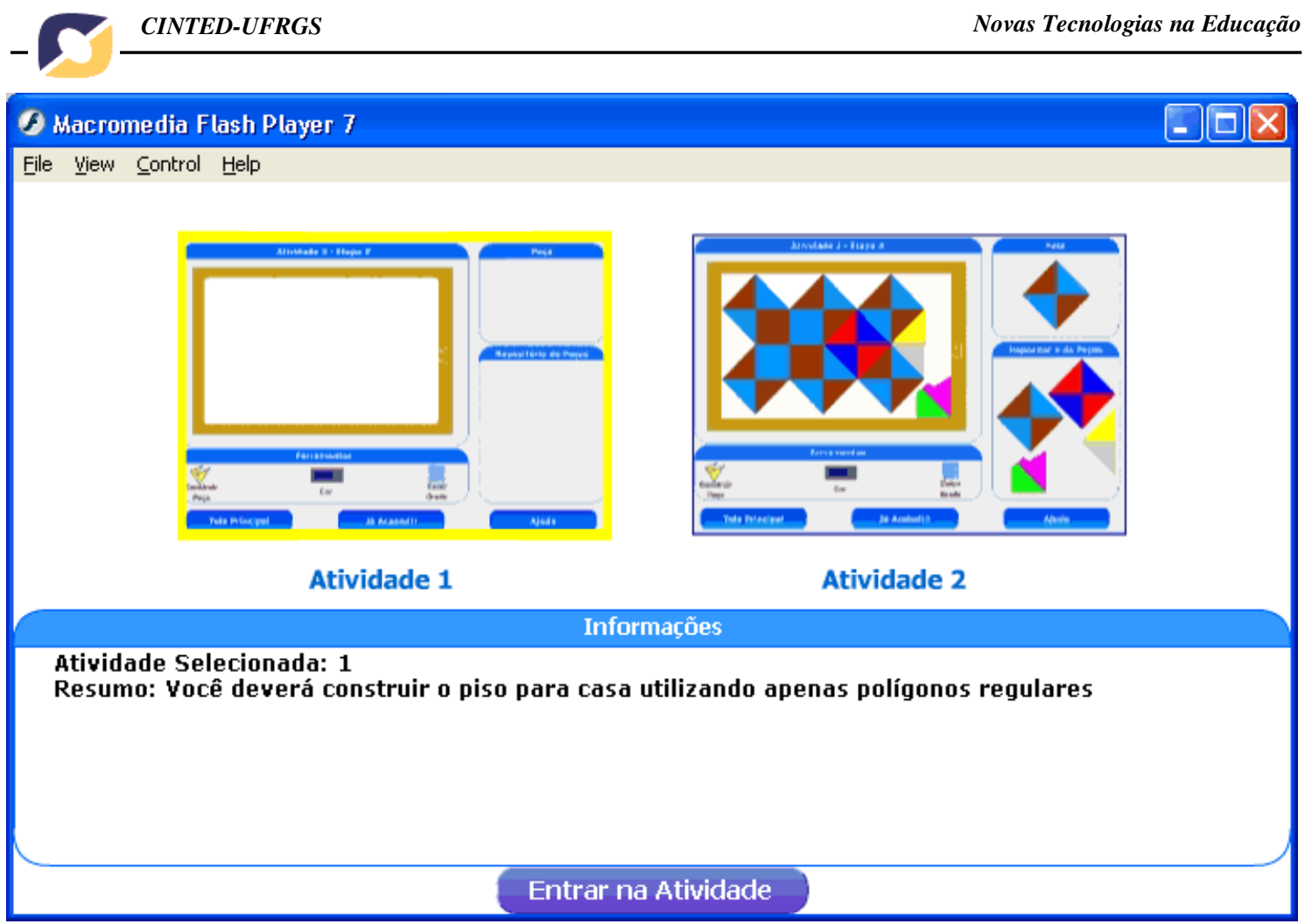

\section{Referências}

Parâmetros Curriculares Nacionais - Ensino Médio. Ministério da Educação, Secretaria de Educação Média e Tecnológica, Brasília, 2002.

Parâmetros Curriculares Nacionais - Ética. Ministério da Educação, Secretaria de Educação Fundamental, Brasília, 2002.Vol. 08.

Vergnaud, G. L’enfant, la mathématique et la réalité, Berne, Peter Lang, 1985.

RIVED / MEC - Rede Internacional Virtual de Educação - RIVED/MEC, Disponível em http://rived.proinfo.mec.gov.br/artigos/ciaem.pdf 